\title{
DISPONIBILIDADES HÍDRICAS NA PROVÍNCIA CÁRSTICA DE ARCOS-PAINS- DORESÓPOLIS, ALTO SÃO FRANCISCO, MINAS GERAIS, BRASIL
}

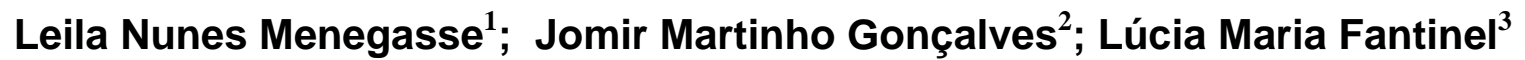

\section{RESUMO}

As bacias hidrográficas ribeirão dos Patos e rio São Miguel $\left(1050 \mathrm{~km}^{2}\right)$, extremo sudoeste do Cráton São Francisco, estruturam-se sobre uma seqüência neoproterozóica metapelítica e rochas carbonáticas do Grupo Bambuí. A diversidade de recursos naturais locais constituem fatores de desenvolvimento, entretanto, têm promovido sérios conflitos ambientais e sócio-econômicos locais. Este estudo é integrado a um projeto interdisciplinar, visando a um novo modelo de desenvolvimento econômico, baseado no turismo científico e ecológico e aproveitamento racional dos recursos naturais, no qual a. água é elemento básico para sua consolidação. Quantificou-se as disponibilidades hídricas da bacia rio São Miguel, baseado em dados fluviométricos, utilizando-se o software Hysep na separação dos escoamentos subterrâneo e superficial. Verificou-se existir ótima correlação estatística entre o escoamento total medido na estação e o excedente hídrico estimado por Thornthwaite-Mather, $\left(r^{2}=0,72 ; P=0,00004\right)$, permitindo aplicá-lo na bacia ribeirão dos Patos (sem dados fluviométricos), adotando-se os índices subterrâneo e superficial anteriormente obtidos, justificado pela similaridade, morfológica e geológica das bacias. Estimou-se uma contribuição de água subterrânea de 355Mim ${ }^{3} / a n o, ~(68,5 \%$ do escoamento; 25\% da precipitação), da qual apenas $1 \%$ é aproveitado, no abastecimento expansão de setores econômicos relevantes, como a agropecuária a indústria e o turismo.

Palavras-chave: balanço hidrológico - água subterrânea - recurso

\footnotetext{
${ }^{1}$ Depto. Geologia do Instituto de Geociências da Universidade Federal de Minas Gerais. Av. Antônio Carlos, 6627, B. Horizonte, MG. CEP 31270-901- Tel:314995424 -Fax:314995410 - Email:menegase@lcc.ufmg.br

${ }^{2}$ Depto. Geografia do Instituto de Geociências da Universidade Federal de Minas Gerais. Av. Antônio Carlos, 6627, B. Horizonte, MG. CEP 31270-901-Tel: 312747717. E-mail:jomir@horizontes.net

${ }^{3}$ Depto. Geologia do Instituto de Geociências da Universidade Federal de Minas Gerais. Av. Antônio Carlos, 6627, B. Horizonte, MG. CEP 31270-901- Tel:314995424 -Fax:314995410 - Email:Ifantinel@uol.com.br
} 


\section{Introdução}

Para a determinação as disponibilidades hídricas de uma determinada região faz-se necessário a realização do balanço hidrológico, o qual quantifica todos os componentes do sistema hídrico, ou seja a precipitação, a evapotranspiração e os escoamentos superficial e subterrâneo. Os dois primeiros parâmetros podem ser medidos direta ou indiretamente em estações climatológicas, enquanto que o escoamento total, em estações fluviométricas.

A caracterização hidrológica, entretanto, depende de um número relativamente elevado de anos de leitura e da consistência dos dados hidroclimatológicos. Considerando a extensão territorial do Brasil e a grande quantidade de mananciais, raras são as estações que dispõem destes dados, o que tem levado ao uso de métodos empíricos e de fácil aplicação, como o de Thornthwaite-Mather (in Tubelis e Nascimento, 1980), para realização do balanço hídrico climático. O mesmo estima, dentre outros parâmetros, o valor do escoamento total, de interesse aos estudos hidrológicos empregando apenas os dados de precipitação e temperatura do ar.

$\mathrm{Na}$ área deste trabalho, envolvendo duas bacias hidrográficas contíguas (ribeirão dos Patos e do rio São Miguel), a presença de uma estação fluviométrica em uma delas (rio São Miguel), permitiu a determinação dos escoamentos total, subterrâneo e superficial nesta bacia, bem como a estimativa do excedente hídrico (ou escoamento total) por Thornthwaite-Mather, com o objetivo de comparação deste com o valor medido para a validação deste método estimativo e sua posterior aplicação na bacia do ribeirão dos Patos.

Este trabalho é parte integrante do Projeto interdisciplinar e interinstitucional "A Província cárstica de Arcos-PainsDoresópolis - uma região adequada à indução de um projeto de desenvolvimento sustentável" sob coordenação do Instituto de Geociências da Universidade Federal de Minas Gerais. O projeto visa ao mapeamento e caracterização dos recursos naturais e da dinâmica ambiental no sistema cárstico, de forma a nortear a elaboração de propostas de um novo modelo de desenvolvimento sócio-econômico na região.

No tocante ao estudo dos recursos hídricos deste projeto em andamento, os estudos das litofácies carbonáticas, por meio da caracterização das estruturas, texturas, características diagenéticas e composição química permitirão caracterizar a ocorrência da porosidade secundária (fraturas e canais de dissolução cársticas), estreitamente 
relacionadas à circulação das águas subterrâneas e à capacidade de armazenamento dos aqüíferos.

\section{Objetivos}

O objetivo do estudo é a quantificação das disponibilidades hídricas subterrâneas e superficiais da Província Cárstica de Arcos-PainsDoresópolis, visando à geração de dados e de informações hidrológicas indispensáveis ao planejamento do uso racional da água e à formulação de estratégias de proteção deste recurso na região, no contexto de desenvolvimento proposto no projeto no qual insere-se este trabalho. Os usos da água reportam ao consumo humano, agropecuária, indústria minerária e turística em potencial.

\section{Importância do estudo}

A área de estudos compreende as duas sub-bacias hidrográficas contíguas ribeirão dos Patos $\left(530 \mathrm{~km}^{2}\right)$, e rio São Miguel $\left(520 \mathrm{~km}^{2}\right)$, as quais estão delimitadas pelas coordenadas $28^{\circ} 08^{\prime}$ a $20^{\circ} 30^{\prime}$ de latitude sul e $45^{\circ} 30^{\prime}$ a $45^{\circ} 58^{\prime}$ de longitude oeste (Figura1), ambas tributárias diretas do alto rio São Francisco. Localizada a cerca de $220 \mathrm{~km}$ a sudoeste do município de Belo Horizonte, a área abrange todo o município de Pains e pequena parte dos municípios de Arcos, Doresópolis,
Iguatama, Córrego Fundo Formiga, Pimenta e Piumhi.

A região abriga um leque de recursos naturais importantes $e$ diversificados de elevado potencial econômico. Citam-se as rochas carbonáticas (calcários e dolomitos), de características adequadas à produção da cal, cimento e corretivos agrícolas; os variados tipos de solos favoráveis a uma boa diversificação da produção agrícola; abundância relativa de água, com grande potencial de renovação por meio das interconexões do relevo cárstico com o sistema superficial; ricos acervos espeleológico e paleontológico de reconhecido valor a nível nacional; e as belas paisagens cársticas onde inserem-se os ricos biomas.

As atividades econômicas tradicionalmente praticadas e de maior peso na economia local (indústria minerária de cimento e cal e o setor agropecuário) têm resultado na degradação ambiental e nas disparidades sócio-econômicas intra e intermunicipais. Há o favorecimento das áreas de concentração das indústrias de transformação de calcário no município de Arcos, geradoras de melhores emprego e renda, às custas das atividades degradantes em Pains pela extração do calcário, em detrimento do incontestável potencial turístico aí existente. De outra parte, a expansão 
descontrolada da agropecuária, deprime deste importante fator de manutenção do a cobertura vegetal natural, em prejuízo equilíbrio hidrológico.

Figura 1 - Localização da área de estudos

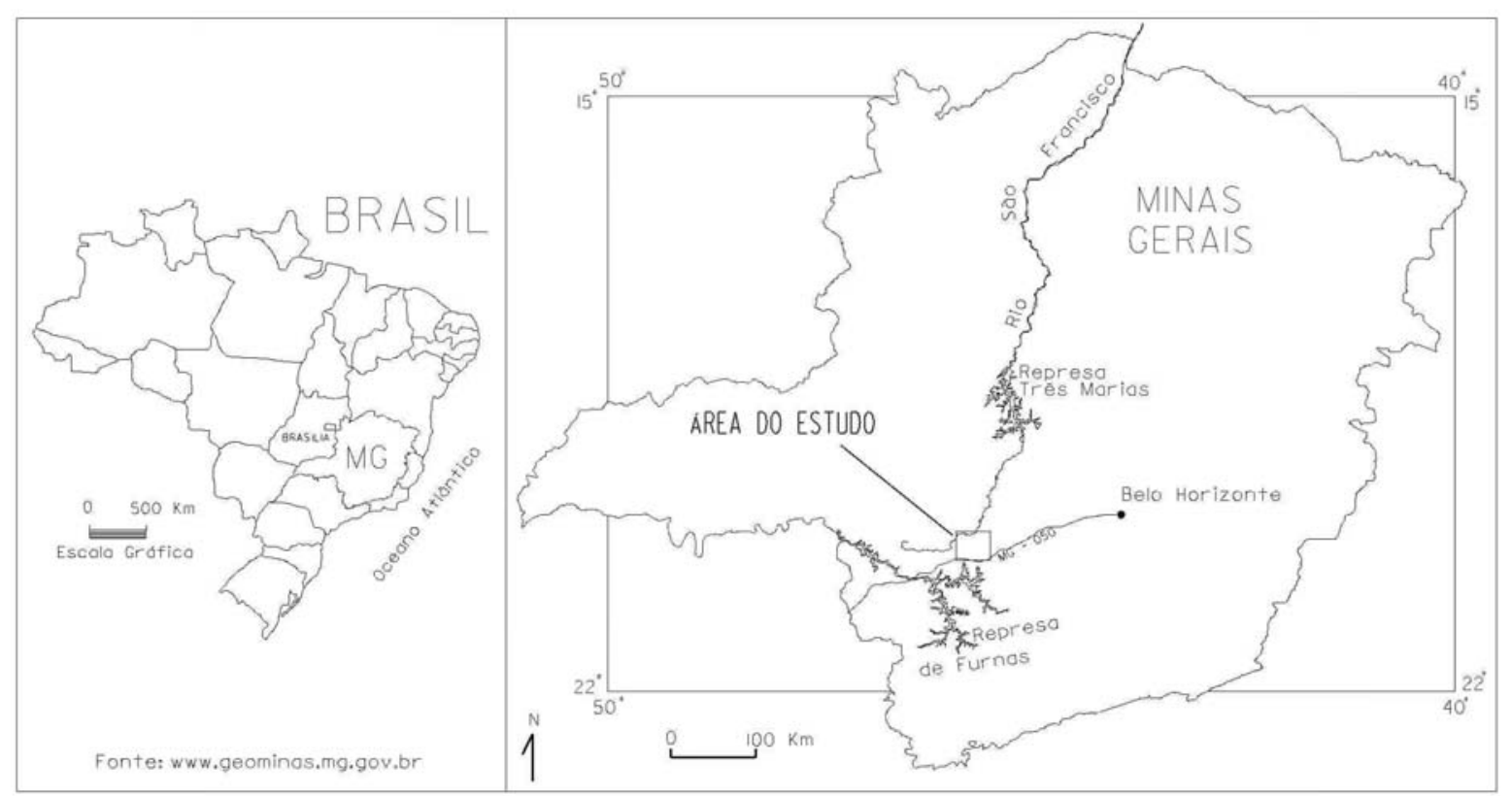

O conjunto das riquezas naturais já colhida é de cultivo de milho para ração citadas, em abundância na região, animal) conduziria ao aproveitamento favorece à indução de um novo modelo mais eficiente da potencialidade dos de desenvolvimento econômico, solos. Em ambos os casos a água é a fundamentado no uso racional e base para o desenvolvimento destes sustentado dos recursos naturais, de setores, sendo indispensável, para tanto, forma a restabelecer o equilíbrio destas a quantificação da sua distribuição no disparidades sócio econômicas.

A implantação de uma Unidade de tempo e no espaço físico superficial e em subsuperfície, objeto maior deste Conservação ambiental no setor oeste estudo. da área (bacia dos Patos), por exemplo, adequadamente estruturado, concorreria para o desenvolvimento econômico dos 3. Caracterização física da área Clima municípios de Pains e Doresópolis, com a efetivação de um programa de turismo Considerando-se os dados da ecológico, científico e rural. O incentivo orientado de uma maior diversificação dos cultivos agrícolas $(60 \%$ da área 4

estação meteorológica mais próxima da área de estudo (Bambuí), a classificação climática de Köppen é do tipo Cwa, clima temperado brando com verão quente e 
úmido e inverno seco. A temperatura média anual é de $20,7^{\circ} \mathrm{C}$, sendo julho o mês mais frio, com temperatura média de $16,3^{\circ} \mathrm{C}$, e janeiro o mais quente, com a média de $23,3^{\circ} \mathrm{C}$. A precipitação média anual local é de $1344 \mathrm{~mm}$.

\section{Geologia}

A Província Cárstica de Arcos Pains - Doresópolis , onde estão inseridas as duas bacias hidrográficas deste estudo, constitui uma região de ocorrência das rochas carbonáticas e silto-argilosas pertencentes ao Grupo Bambuí (Proterozóico Superior) no limite sudoeste da porção sul do Cráton do São Francisco, em contato com a faixa de dobramentos Brasília, desenvolvida no Ciclo Brasiliano.

Especificamente na região, os calcários ocorrem sob forma de lentes entre os filitos do Grupo Bambuí, fazendo do contexto geológico da região, um mosaico de afloramentos calcários e filitos sucessivos, permitindo a ocorrência de zonas cársticas isoladas em meio a rochas não carbonáticas (Figura 2). Em certos locais os calcários encontram-se deformados (dobrados), permitindo maior infiltração e percolação das águas pluviais para zonas mais profundas dos aqüíferos, e no restante da área, os calcários são horizontalizados, ou pouco deformados. O grau de deformação aumenta no sentido de leste para oeste, tendo sido individualizadas duas áreas por MuzziMagalhães (1989): uma com calcários horizontais e outra com calcários dobrados, cujo limite orienta-se aproximadamente ao longo do alto rio São Miguel até a altura da sede de Pains, sofrendo um deslocamento brusco de $2 \mathrm{~km}$ para leste. As estruturas tectônicas mais relevantes que ocorrem na área são as falhas inversas e de empurrão (NS e NNE-SSW), as falhas transcorrentes sinistrais (N70W) e dobras flexurais.

Muzzi-Magalhães (1989) propôs uma divisão do Grupo Bambuí nesta porção sudoeste do Cráton em 4 fácies, da base para o topo: conglomerática, pelítica, carbonática e psamo-pelítica, sendo que a fácies carbonática teria sido subdividida em 6 níveis distintos (icalcilutitos e margas, ii-alcarenitos, iicalcarenito dolomítico, iv-dolarenito, vcalcarenito estromatolítico; dolarenito calcítico; calcirrudito dolomítico e vicalcarenito; calcilutitos superiores.

\section{Geomorfologia}

A geomorfologia das bacias são marcadas pelo típico relevo cárstico bem desenvolvido ao nível do exo e endocarste. Estudos recentes (Saadi, 1991, 1993) têm mostrado uma importante influência da tectônica recente no condicionamento da 
geomorfogênese do carste nesta região, associado a um elevado índice pluviométrico.

Destacam-se na área três domínios cársticos, separados por ocorrências de filitos: o de Pains, de $\operatorname{Arcos}$ e o de Doresópolis, que apesar de seus limites não serem muito precisos, em certos casos, os domínios são individualizados pelas concentrações de inúmeras formas cársticas, onde destacam-se as grutas, cavernas, abrigos, surgências, sumidouros, lapiás, dolinas, uvalas, poliéz, paredões, verrugas, dentre outros. Dentro das cavidades endocársticas, destacam-se os espeleotemas como estalagmites e estalactites, resultantes de atividade intempérica das águas.

As águas superficiais distribuem-se por uma rede hidrográfica tipicamente pouco densa, favorecido pela infiltração direta nas fissuras dos calcários e nas feições de absorção cársticas (sumidouros, simas, etc.). Destacam-se os seguintes cursos d'água principais (Figura 3): i) rio São Francisco, que compreende o nível de base regional, a norte da área; ii) rio São Miguel (53 km), que atravessa o município de Pains no sentido N-S; iii) ribeirão dos Patos sob iminente controle estrutural; e iv) rio Candongas, o qual drena para o baixo curso do rio São Miguel, no município de Arcos.
Os cursos de Patos e São Miguel nascem nas cotas 860 e 875 metros, desaguando nas cotas 632 e 630, respectivamente. As maiores altitudes da área encontram-se no extremo sudoeste, na serra da Pimenta, à 1.200 metros, cujo relevo foi esculpido sobre rochas quartzíticas.

O clima tropical local é responsável pela sazonalidade da dinâmica hídrica regional, modificando significativamente as paisagens e seus atrativos turísticos entre as estações úmida e seca. $\mathrm{Na}$ estação úmida, os grandes volumes hídricos permitem o surgimento de belos cenários em dolinas, ressurgências, sumidouros, ativação de vales secos.

\section{Vegetação}

A vegetação nativa da área é do tipo savana (cerrado), com gradações que vão das gramíneas do campo limpo à vegetação densa e de maior porte do cerradão (Radam Brasil, 1983). Observa-se, entretanto, a substituição da vegetação nativa pelo uso agrícola.

Nas áreas cársticas, verifica-se um caráter estacional da vegetação de florestas estacional decidual, sendo este tipo vegetacional conhecido na área de estudo como "Mata de Pains", entre as altitudes de 500 a 800 metros, revestindo os afloramentos calcários (Barbosa, 1961). A sua principal característica é uma fisionomia sempre 
verde nos meses chuvosos e mineradoras e nos locais de produção completamente seca na estiagem. Esta (36\% dos 72 poços cadastrados até o vegetação vem sendo arrasada pela momento). Os consumos são extração mineral e pelo uso agrícola, relacionados aos processos de produção predominando a pastagem extensiva da cal hidratada, resfriamento de (Radam Brasil, 1983).

\section{Usos da água na área de estudos}

Destaca-se a grande importância social e econômica da água subterrânea na área, com larga utilização no abastecimento público nas sedes de todos os municípios, distritos, vilas e bairros mais afastados. No município de Pains o abastecimento da sede é realizado por meio de captação de uma nascente $\left(80 \mathrm{~m}^{3} / \mathrm{h}\right)$ e nas demais localidades por meio de poços tubulares. O consumo doméstico da água subterrânea é também verificada na área rural, por meio de poços tubulares e cisternas, servindo ainda à irrigação de pequenas plantações de subsistência e dessedentação de animais.

No setor agrícola a água subterrânea é sub utilizada, devido ao próprio cultivo do milho na estação chuvosa, o qual ocupa em média $60 \%$ da área colhida.

A indústria da mineração do calcário, base econômica da região, é a maior consumidora de água tanto subterrânea como superficial, tendo sido constatada a utilização de pelo menos um poço tubular profundo nas caldeiras, lavagem de equipamentos e aspersão das áreas de tráfego de caminhões, sendo este o principal consumo.

A grande utilização da água subterrânea na região deve-se ao rápido e precário escoamento superficial neste tipo de terreno, em especial nos meses de estiagem, quando as dolinas e córregos encontram-se praticamente secos, e, em alguns casos, devido à poluição antrópica de determinados cursos d'água.

Dados preliminares (amostra de 22 poços) apontam vazões relativamente modestas dos poços perfurados nas rochas carbonáticas para este tipo de aqüífero neste contexto climático (média: $8 \mathrm{~m}^{3} / \mathrm{h}$; mediana: $8 \mathrm{~m}^{3} / \mathrm{h}$; mínimo e máximo: 1 e $20 \mathrm{~m}^{3} / \mathrm{h}$, respectivamente). Mesmo assim, os poços são uma alternativa vantajosa pela constância das vazões durante todo o ano.

\section{Metodologia}

A área deste estudo, compreendendo as duas bacias hidrográficas contíguas, ribeirão dos Patos $\left(1030 \mathrm{~km}^{2}\right)$ e rio São Miguel $\left(1020 \mathrm{~km}^{2}\right)$, possui uma estação 
fluviométrica apenas nesta última, o que permitiu a realização, nesta bacia, do balanço hidrológico por meio da separação de hidrogramas, utilizando-se o programa computacional Hysep da U.S. Geological Survey para a separação do escoamento subterrâneo e superficial. Os dados de entrada são as descargas diárias e as saídas incluem tabelas e gráficos com os dados de escoamento básico e superficial, a freqüência e duração da vazão do rio. A vantagem no uso deste programa consiste na remoção de inconsistências inerentes ao métodos manuais de separação de uma hidrógrafa de rio e é baseada em uma técnica matemática que imita a forma humana de separação de hidrogramas, permanecendo, por isso, como um processo ainda subjetivo.

Por meio do balanço hídrico climático de Thornthwaite-Mather (in Tubelis e Nascimento, 1980), estimou-se anualmente a evapotranspiração e o excedente hídrico (ou escoamento total), para cada uma das bacias (dados de entrada: temperatura média mensal e a precipitação mensal), utilizando-se 0 aplicativo Balasc do Centro de Ensino e Pesquisa em Agricultura da Universidade Estadual de Campinas.

O excedente hídrico da bacia do rio São Miguel foi correlacionado estatisticamente ao escoamento total medido na estação fluviométrica para 8 verificar-se a precisão deste método estimativo na região. Verificado existir uma ótima correlação, estimou-se o escoamento total na bacia do ribeirão dos Patos por Thorthwaite-Mather e por meio da equação de regressão. Adotouse os índices de escoamento subterrâneo e superficial da bacia do rio São Miguel, justificada pela continuidade lateral e elevada similaridade morfológica, geológica e dimensional de ambas as bacias.

\section{Dados utilizados}

\section{Pluviometria}

Foram utilizados dados consistidos de 15 anos (1975 a 1989) de quatro estações pluviométricas sendo que três localizam-se nas imediações da área (Figura 3).

\section{Fluviometria}

Para caracterização do escoamento na área existe uma única estação fluviométrica (estação de Calciolândia), localizada no baixo curso do rio São Miguel, cuja área de drenagem é de $277 \mathrm{~km}^{2}$ (Figura 3). Utilizou-se dados diários consistidos de 15 anos (1975 a 1989) para a geração do hidrograma e separação dos escoamentos superficial e subterrâneo. 
Temperatura do ar

Devido à ausência de medidas de temperatura nas estações pluviométricas, foi utilizado o método estimativo apresentado em Tubelis e Nascimento (1980, p.83), com base na latitude e altitude das estações. Tal método foi obtido através de equações lineares de regressão dos dados das estações do INMET (Instituto Nacional de Meteorologia), aplicando-se os coeficientes estatísticos para estimativa de temperaturas médias do ar no Estado de Minas Gerais.

Este método foi testado na estação meteorológica de Bambuí (30km a norte da área), para o período de 1972 a 1990. A temperatura média anual estimada foi de $20,9^{\circ} \mathrm{C}$, enquanto a medida foi de $20,7^{\circ} \mathrm{C}$. A nível mensal as diferenças entre o valor estimado e o medido ficaram entre $-0,8^{\circ} \mathrm{C}$ e $+1,3^{\circ} \mathrm{C}$. Para efeito deste estudo, portanto, considerou-se este método bastante adequado para a estimativa das temperaturas médias mensais em cada uma das 4 estações pluviométricas da área, localizadas a diferentes altitudes, entre 606 e 806 metros.

\section{Resultados}

As temperaturas médias anuais variam de $19,8^{\circ} \mathrm{C}$ na porção baixa da área a $20,9^{\circ} \mathrm{C}$ na região das nascentes, com média de $20,1^{\circ} \mathrm{C}$.
São pequenas as variações locais das precipitações anuais na área, com média de $1344 \mathrm{~mm}$, sendo os valores mais elevados concentrados no extremo sudoeste da área, sob influência das chuvas orográficas da serra da Pimenta, onde a precipitação média anual chega a 1500mm, na estação de Piumhí (Figura 3).

O balanço hídrico climático por Thornthwaite-Mather para a área total das bacias hidrográficas, mostra dois períodos distintos, sendo um com excedente hídrico, de novembro a abril e o outro com deficiência hídrica, de maio a setembro, com a reposição no mês de outubro. Estes períodos coincidem aproximadamente aos meses úmidos, de outubro a março (81\% da precipitação anual), e aos meses secos, de abril a setembro.

As disponibilidades hídricas subterrâneas e superficiais foram determinadas individualmente para cada uma das bacias hidrográficas, sendo que na bacia do rio São Miguel, a existência da estação fluviométrica de Calciolândia $\left(277 \mathrm{~km}^{2}\right)$ permitiu um maior grau de confiabilidade nesta determinação, servindo de base para os cálculos na bacia do ribeirão dois Patos.

As descargas médias anuais, totais, subterrâneas e superficiais, calculadas a partir dos dados da estação de Calciolândia são, respectivamente, de 
465mm, 318mm e 146mm (Tabela $1 \mathrm{em}$ anexo). Da vazão média anual da bacia do rio São Miguel, $7,6 \mathrm{~m}^{3} / \mathrm{s}$ (242Mim 3 /ano), resulta uma contribuição subterrânea de $68,5 \%$ do escoamento total e $24 \%$ da precipitação, isto é, 166 milhões de $\mathrm{m}^{3} / a n o$. Há uma preponderância da contribuição subterrânea em relação à superficial em todos os meses do ano, sendo mais significativo nos meses secos, de abril a outubro (Figura 4), alcançando em média $95 \%$ no mês de julho e $54 \%$ em dezembro. Ainda nesta figura, verifica-se um súbido acréscimo do escoamento subterrâneo entre os meses de novembro e dezembro. Estes fatores indicam haver boas condições de recarga (fraturas e feições de absorção cárstica) e capacidade de renovação das águas subterrâneas, além de um bom grau de interconexão entre o sistema aqüífero e o superficial.

$\mathrm{Na}$ tabela 2 acham-se os resultados do balanço hídrico climático. Os valores estimados de excedente hídrico anuais comparados ao escoamento medido na estação de Calciolândia, mostram a grande proximidade entre eles (Figura 5), com uma diferença de apenas 5,7\% (Tabela 1 em anexo). Quando são correlacionados estatisticamente, obtémse um elevado coeficiente de determinação $\left(R^{2}=0,74\right.$ e $\left.P=0,00004\right)$ entre eles (Figura 6). Na Figura 7 constata-se a ausência de qualquer tendência gerada da equação de regressão.

Constata-se que o valor do escoamento total estimado pela equação de regressão na bacia do rio São Miguel (média de 15 anos), coincide com o valor medido na estação (465 mm), apresentando um valor muito baixo da média de erro entre o valor medido e o estimado pela equação $(-0,0019)$. Isto ratifica o ótimo grau de precisão do método de Thorthwaite-Mather, para uma longa série de anos, para obtenção do escoamento total.

\begin{tabular}{|l|c|c|c|c|c|}
\hline \multicolumn{1}{|c|}{ Bacia } & $\begin{array}{c}\text { Precipi- } \\
\text { tação }\end{array}$ & $\begin{array}{c}\text { Evapotrans- } \\
\text { piração } \\
\text { potencial }\end{array}$ & $\begin{array}{c}\text { Evapotranspi- } \\
\text { ração real }\end{array}$ & $\begin{array}{c}\text { Deficiência } \\
\text { hídrica }\end{array}$ & $\begin{array}{c}\text { Excedente } \\
\text { hídrico }\end{array}$ \\
\hline rio S. Miguel & 1325 & 937 & 834 & 104 & 491 \\
\hline $\begin{array}{l}\text { rib.dos } \\
\text { Patos }\end{array}$ & 1363 & 937 & 835 & 102 & 529 \\
\hline
\end{tabular}

Tabela 2 - Balanço hídrico climático por Thornthwaite-Mather, em mm/ano (1975 1989).

Na bacia do ribeirão dos Patos os escoamentos total, subterrâneo e 
superficial foram estimados de modo indireto devido à ausência de uma estação fluviométrica na mesma. Nesta condição, tal estimativa pôde ser realizada segundo três métodos, mas fundamentalmente baseados na semelhança física e geológica das duas bacias:

I. diretamente pela estimativa do excedente hídrico na bacia do ribeirão dos Patos, e adotando-se os mesmos coeficientes do escoamentos subterrâneo e superficial da bacia do rio São Miguel;

II. aplicando-se a equação de regressão para cálculo do escoamento total na bacia do rio São Miguel e admitindo-se os mesmos coeficientes dos escoamentos subterrâneo e superficial supracitados;

III. adotando-se os mesmos valores da vazão específica da bacia do rio São Miguel.

Dentre as três alternativas acima mencionadas (Tabela 3) as duas primeiras apresentaram valores muito próximos entre si e um pouco mais elevados do que pelo método III, mostrando maior coerência com as condições desta bacia, quais são a maior precipitação (3\% a mais na precipitação média anual provocou um acréscimo de 7\% no excedente hídrico) e a ligeira maior extensão em área (10 $\mathrm{km}^{2}$ ). De uma forma geral, entretanto, os parâmetros do balanço hidrológico não diferem muito de uma bacia para outra em termos quantitativos, devido à grande similaridade entre ambas. A Figura 8 ilustra a relação entre os componentes principais do balanço hidrológico na área total, admitindo-se os dados do método II para a bacia do ribeirão dos Patos.

\begin{tabular}{|c|c|c|c|c|c|c|c|}
\hline \multicolumn{2}{|c|}{ Bacia } & \multicolumn{2}{|c|}{$\begin{array}{c}\text { Vazão média } \\
\left(\mathrm{m}^{3} / \mathrm{s}\right)\end{array}$} & \multicolumn{2}{|c|}{$\begin{array}{c}\text { Escoamento } \\
(\mathrm{mm})\end{array}$} & \multicolumn{2}{|c|}{$\begin{array}{c}\text { Volume } \\
\left(\mathrm{Mim}^{3}\right)\end{array}$} \\
\hline & & Total & Subterrânea & Total & $\begin{array}{l}\text { Subter- } \\
\text { râneo }\end{array}$ & Total & Subterrâneo \\
\hline São Miguel & & 7,6 & 5,2 & 465 & 319 & 242 & 166 \\
\hline \multirow[b]{3}{*}{ Rib. Patos } & método I & 8,9 & 6,1 & 529 & 362 & 280 & 192 \\
\hline & método II & 8,7 & 6,0 & 506 & 347 & 268 & 189 \\
\hline & método III & 7,8 & 5,3 & 465 & 318 & 245 & 167 \\
\hline
\end{tabular}

Tabela 3 - Síntese dos escoamentos total e subterrâneo anuais

A contribuição de água subterrânea mineração e indústria do calcário (a na área é de 355 milhões de $\mathrm{m}^{3} / \mathrm{anno}$, agricultura predominante é a não mas apesar da sua larga utilização na irrigada), o consumo deste recurso na área para o consumo humano, área é ínfimo, não ultrapassando 1\% 
desta reserva (100 poços com vazão média de $8,0 \mathrm{~m}^{3} / \mathrm{h}$ e $12 \mathrm{~h} /$ dia de bombeamento), ou seja há um aproveitamento de apenas 3,5 milhões de $\mathrm{m}^{3} / a n o$.

\section{Conclusões e considerações}

O método estimativo do escoamento total por ThornthwaiteMather mostrou-se bastante adequado às condições climáticas da área de estudo, conforme demonstrado pela existência de correlação com os valores medidos na estação fluviométrica da bacia do rio São Miguel $\left(r^{2}=0,72\right.$; $\mathrm{P}=0,00004)$, apresentando, inclusive, a mesma média total para os 15 anos amostrados. A importância desta validação foi o maior grau de confiabilidade para o cálculo das disponibilidades hídricas da bacia do ribeirão dos Patos.

Há uma superioridade da contribuição subterrânea em todos os meses do ano, mostrando uma grande capacidade de infiltração das rochas calcárias, e uma elevada contribuição subterrânea $\left(355 \mathrm{Mim}^{3}\right.$ ), fator bastante favorável à expansão da sua utilização em setores de desenvolvimento econômico, como a agropecuária, indústria e turismo.

As condições climáticas e o precário escoamento superficial nesse sistema imprimem especial importância econômica e social ao aproveitamento da água subterrânea na região de estudo. Entretanto, apenas cerca de 1\% deste total é aproveitado, apesar de sua larga utilização no abastecimento público, mineração e indústria do calcário. Isto indica o elevado potencial de consumo para expansão de setores econômicos importantes, como a agropecuária a indústria e o turismo.

\section{Agradecimentos}

À Fundação de Desenvolvimento da Pesquisa (FUNDEP) e ao Centro de Pesquisas Manuel Teixeira da Costa do Instituto de Geociências da UFMG (CPMTC).

\section{Bibliografia}

ALMEIDA, F.F.M. de (1977) O Cráton do São Francisco. Revista Brasileira de Geociências. 7 (4): $349-364$.

AMORIM, M.C. de; ROSATO, L. \& TOMASELLA, J. (1999) Determinação da evapotranspiração potencial do Brasil aplicando o modelo de Thornthwaite a um sistema de informações geográfica. Rev. Bras. de Recursos Hídricos. 4 (3):83 90.

BARBOSA, G.V. (1961) Noticias sobre o Karst na Mata de Pains. Boletim Mineiro de Geografia. Belo Horizonte. 2 (3):3-21. 
CASTILHO, A.S. (1996) Rede Hidrometeorológica e Caracterização Física da Bacia do Alto São Francisco; Sub bacia 40. - Belo Horizonte: CPRM. 34 p.

MUZZI-MAGALHÃES, P. (1989) Análise Estrutural Qualitativa das Rochas do Grupo Bambuí, na Porção Sudoeste da Bacia do São Francisco. Dissertação de mestrado apresentado à UFOP. 100 p.

RADAM BRASIL (1983) Levantamento de recursos Naturais. V. 32. Rio de Janeiro: MME/SG. Folhas Sf 23/24 - Rio de Janeiro/Vitória - 775 p.

SAADI, A. (1991) Ensaio Sobre a Morfotectônica de Minas Gerais: tensões intraplaca, descontinuidades crustais e morfogênese. Tese apresentada para provimento a Professor Titular ao Instituto de Geociências -UFMG. 285 p.

SAADI, A.; MORAIS, M.S.; CARDOSO, G.G.C.. (1998) Evolução Morfotectônica e Carstogênese na Região de Arcos-Pains-Doresópolis. In: Anais do II Simpósio Brasileiro de Geomorfologia. Florianópolis: Revista Geosul. p.341 - 344.

SLOTO, R.A. \& CROUSE, M.Y. (1996) HYSEP: A computer program for streamflow hydrograph separation and analysis. Pennsylvania: USGS. 46 p.

TUBELIS, A. \& NASCIMENTO, F.J.L. (1980) Meteorologia Descritiva. Fundamentos e Aplicações Brasileiras. São Paulo: Ed. Nobel. 374 p. 


\begin{tabular}{|c|c|c|c|c|c|c|c|c|c|c|}
\hline \multirow[t]{2}{*}{ Ano } & \multicolumn{3}{|c|}{$\begin{array}{c}\text { Escoamento } \\
\text { médio } \\
\text { (estação } \\
\text { fluviométrica de } \\
\text { Calciolândia) } \\
\\
(\mathrm{mm})\end{array}$} & \multicolumn{3}{|c|}{$\begin{array}{c}\text { Vazão específica } \\
\text { (estação } \\
\text { fluviométrica } \\
\text { de Calciolândia) } \\
\left(\times 10^{-3}\right) \\
\left(\mathrm{m}^{3} / \mathrm{s}^{2} / \mathrm{km}^{2}\right)\end{array}$} & \multirow[t]{2}{*}{$\begin{array}{c}\text { Excedente } \\
\text { Hídrico } \\
\text { (Thornth- } \\
\text { waite- } \\
\text { Mather) } \\
\text { (mm) }\end{array}$} & \multirow[t]{2}{*}{$\begin{array}{c}\begin{array}{c}\text { Precipita- } \\
\text { ção média } \\
\text { ponderada } \\
\text { de } \\
\text { Thiessem }\end{array} \\
(\mathrm{mm})\end{array}$} & \multirow[t]{2}{*}{$\begin{array}{c}\text { Coefi- } \\
\text { ciente } \\
\text { Escoa- } \\
\text { mento } \\
\text { Subter- } \\
\text { râneo/Total } \\
(\%)\end{array}$} & \multirow[t]{2}{*}{$\begin{array}{c}\text { Coefi- } \\
\text { ciente } \\
\text { Escoa- } \\
\text { mento } \\
\text { Subter- } \\
\text { râneol } \\
\text { Precip } \\
\text { itação } \\
(\%)\end{array}$} \\
\hline & Total & \begin{tabular}{|c|} 
Subter- \\
râneo
\end{tabular} & $\begin{array}{c}\text { Super- } \\
\text { ficial }\end{array}$ & Total & $\begin{array}{c}\text { Subter- } \\
\text { rânea }\end{array}$ & $\begin{array}{c}\text { Super- } \\
\text { ficial }\end{array}$ & & & & \\
\hline 1975 & 347 & 218 & 129 & 11,0 & 6,9 & 4,1 & 498 & 1296 & 62,9 & 16,8 \\
\hline 1976 & 368 & 275 & 93 & 11,6 & 8,7 & 2,9 & 475 & 1394 & 74,8 & 19,7 \\
\hline 1977 & 390 & 253 & 137 & 12,3 & 8,0 & 4,3 & 393 & 1197 & 64,9 & 21,1 \\
\hline 1978 & 459 & 284 & 175 & 14,5 & 9,0 & 5,6 & 572 & 1448 & 61,9 & 19,6 \\
\hline 1979 & 595 & 428 & 166 & 18,8 & 13,6 & 5,3 & 609 & 1517 & 72,1 & 28,2 \\
\hline 1980 & 553 & 396 & 157 & 17,5 & 12,5 & 4,9 & 455 & & 71,6 & 30,4 \\
\hline 1981 & 340 & 193 & 147 & 10,8 & 6,1 & 4,7 & 548 & 135 & 56,8 & 14,3 \\
\hline 1982 & 713 & 496 & 218 & 22,6 & 15,7 & 6,9 & 489 & 1252 & 69,5 & 39,6 \\
\hline 1983 & 1075 & 744 & 331 & 34,1 & 23,6 & 10,5 & 926 & 1835 & 69,2 & 40,6 \\
\hline 1984 & 245 & 196 & 49 & 7,8 & 6,2 & 1,6 & 269 & 1072 & 79,9 & 18,3 \\
\hline 1985 & 634 & 452 & 182 & 20,1 & 14,3 & 5,8 & 673 & 1498 & 71,3 & 30,2 \\
\hline 1986 & 368 & 218 & 151 & 11,7 & 6,9 & 4,8 & 469 & 1198 & 59,1 & 18,2 \\
\hline 1987 & 385 & 281 & 104 & 12,2 & 8,9 & 3,3 & 380 & 1215 & 73,0 & 23,1 \\
\hline 1988 & 171 & 132 & 40 & 5,4 & 4,2 & 1,3 & 165 & 987 & 76,9 & 13,3 \\
\hline 1989 & 327 & 208 & 119 & 10,4 & 6,6 & 3,8 & 448 & 1306 & 63,6 & 15,9 \\
\hline Média & 465 & 318 & 146 & 14,7 & 10,1 & 4,6 & 491 & 1325 & 68,5 & 23,3 \\
\hline Mínima & 171 & 132 & 40 & 5,4 & 4,2 & 1,3 & 165 & 987 & 56,8 & 13,3 \\
\hline Máxima & 1075 & 744 & 331 & 34,1 & 23,6 & 10,5 & 926 & 1835 & 79,9 & 40,6 \\
\hline D.padrão & 224 & 159 & 70 & 7,1 & 5,1 & 2,2 & 175 & 196 & 6,7 & 8,6 \\
\hline Mediana & 385 & 275 & 147 & 12,2 & 8,7 & 4,7 & 475 & 1303 & 69,5 & 19,7 \\
\hline
\end{tabular}

Tabela 1 - Parâmetros hidrológicos da Bacia do rio São Miguel 


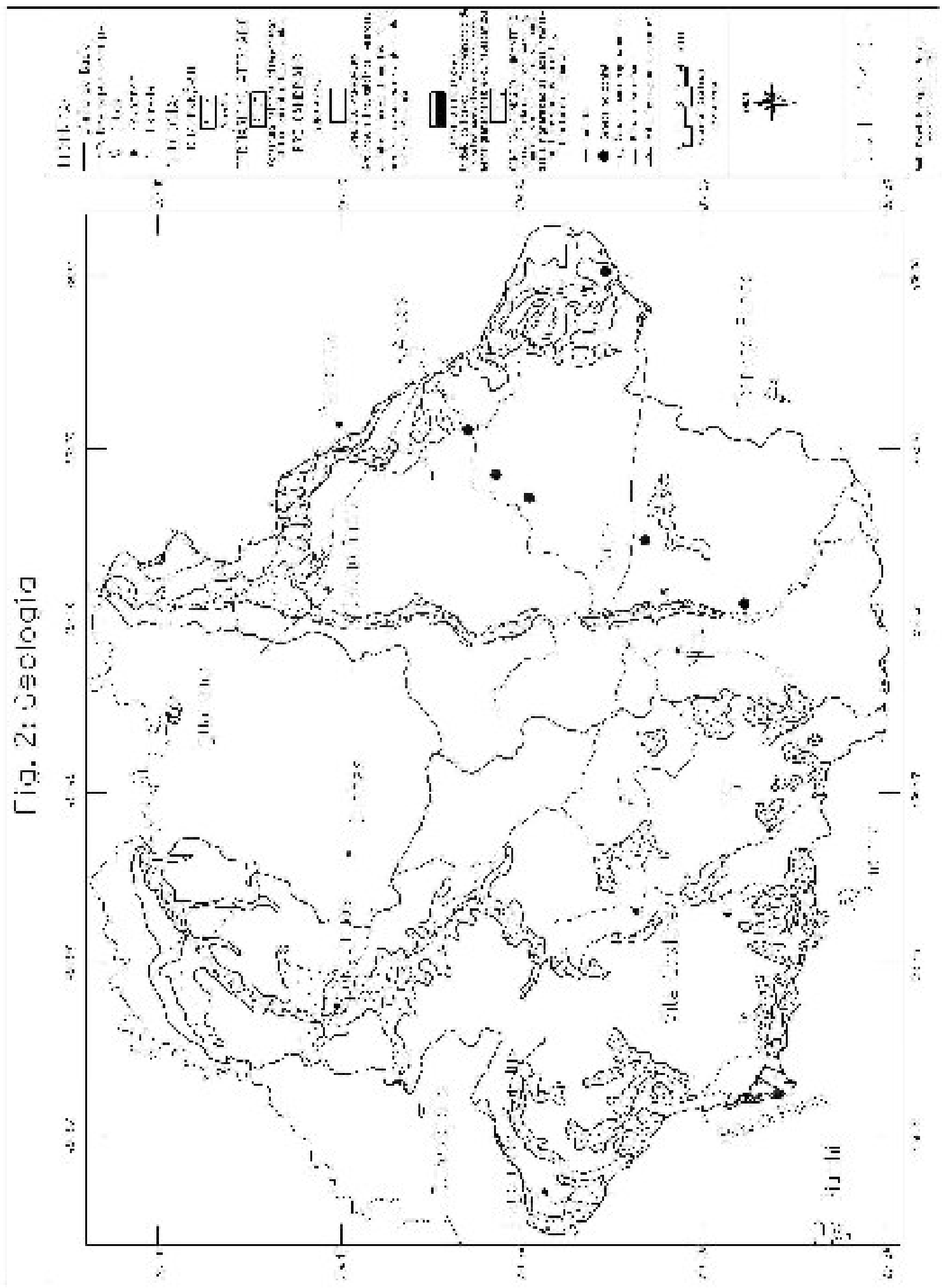




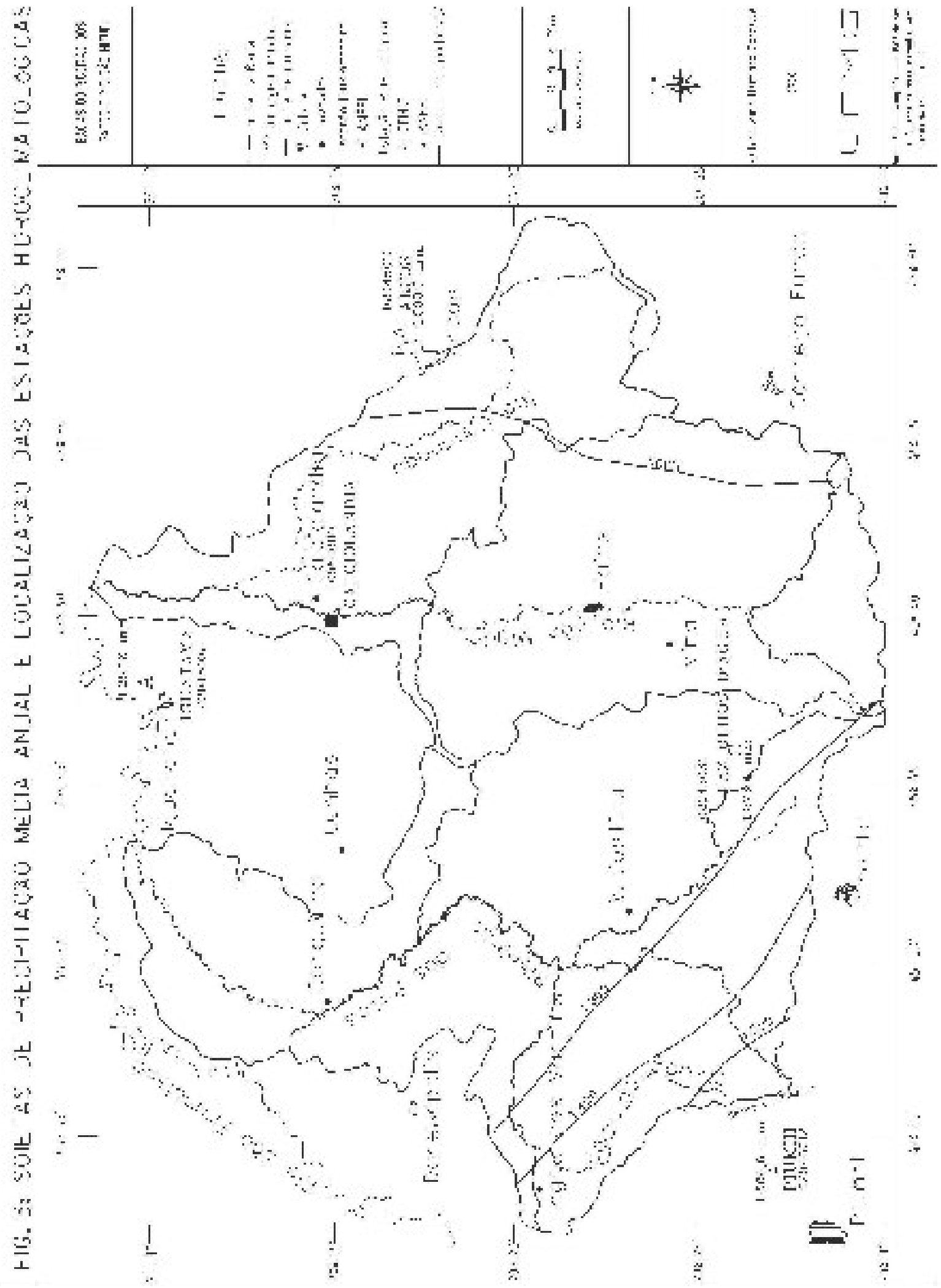




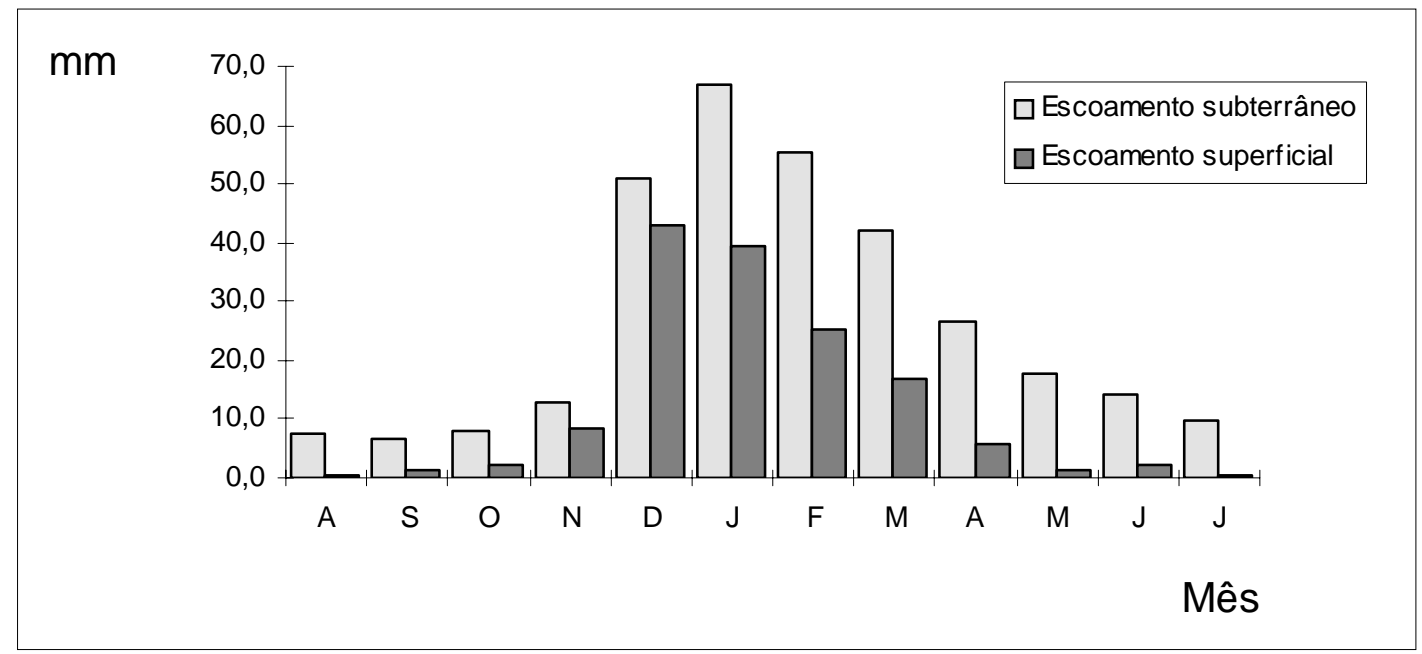

Figura 4: Estimativa média mensal dos escoamentos subterrâneo e superficial na bacia do rio São Miguel - estação fluviométrica de Calciolândia (1975 -1989)

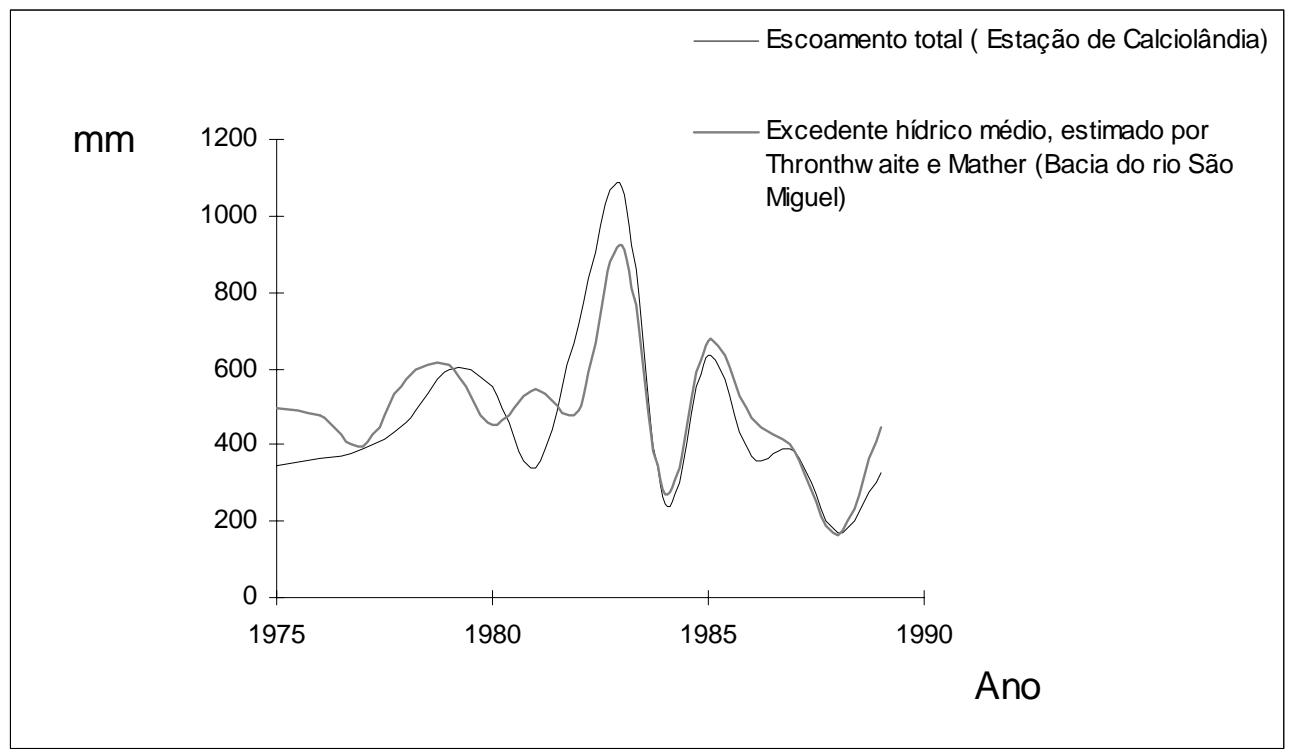

Figura 5. Comparação entre as descargas de Calciolândia e o excedente hídrico estimado por Thornthwaite-Mather para a bacia do rio São Miguel 


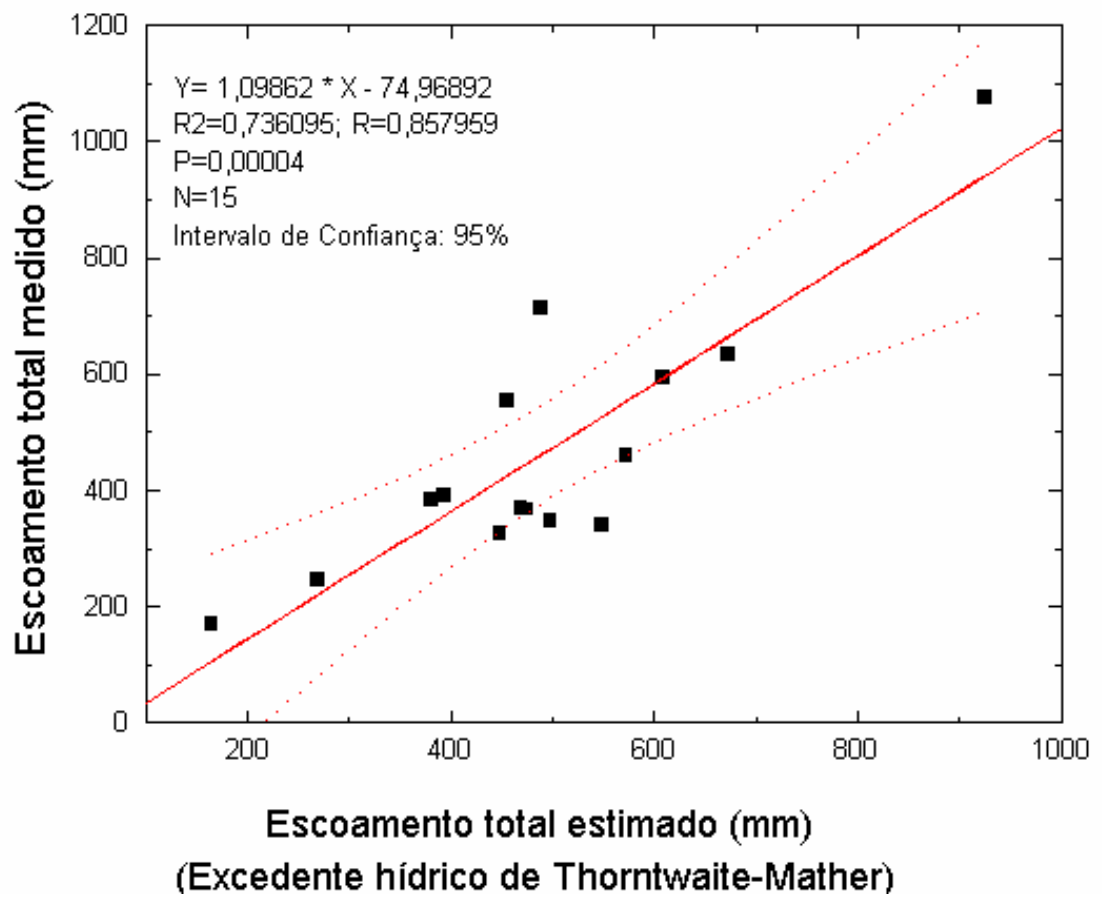

Figura 6 - Correlação linear entre os escoamentos medido e estimado na bacia do rio São Miguel

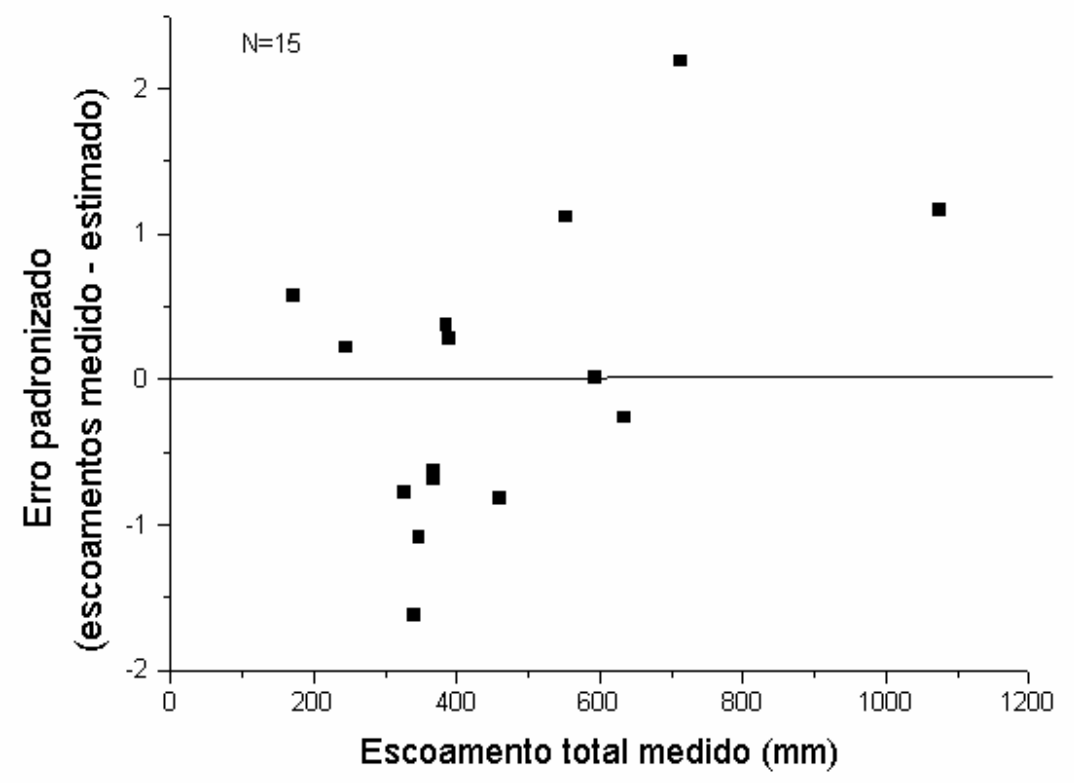

Figura 7 - Análise dos resíduos a partir da equação para predição do escoamento total 


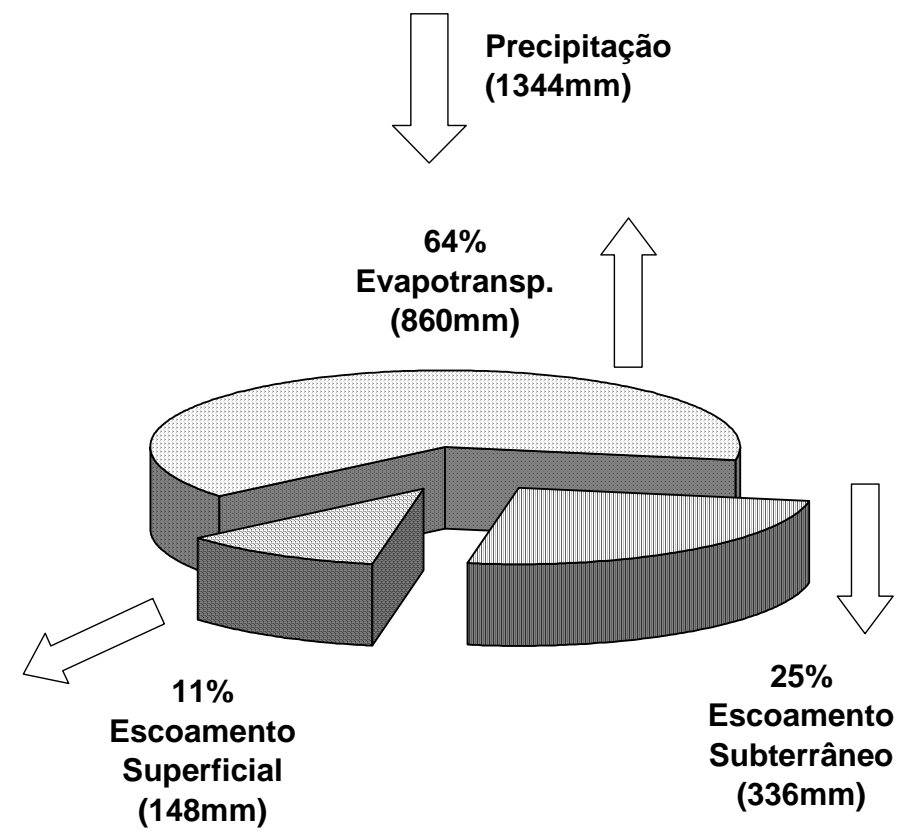

Figura 8 - Balanço Hidrológico geral da área de estudos 